\title{
A problemática dos valores no mundo contemporâneo *.
}

\author{
Miguel Reale \\ Catedrático de Filosofia de Direito na Facul- \\ dade de Direito da Universidade de São Paulo \\ - Presidente do Instituto Brasileiro de \\ Filosofia.
}

1. Sejam as minhas primeiras palavras de agradecimento pela gentileza de vossa acolhida. Ao chegar a Aracajú, após 27 anos de ausência, tinha ainda na memória a imagem risonha de uma pequenina capital, que mal anunciava as transformações por que já passou, e pelas quais se pode prever mais uma pujante metrópole do Nordeste. Mas se a cidade se transmudou, a cordialidade continua sendo a mesma, inalterável o espírito, imutável a dedicação às coisas de ordem ética e cultural. Sòmente um povo com tal capacidade poderia expressarse, como se expressa, através de representantes tão altos no cenário espiritual do país. Não há brasileiro dedicado aos problemas da inteligência que não tenha por Sergipe uma simpatia tôda especial, que brota e se legitima pelo número extraordinário de sergipanos que potenciaram a cultura nacional.

Bastaria lembrar apenas três nomes: Tobias Barketo, Sílvio Romero e João Ribeiro, três expressões que caracterizam aspectos diversos da intelectualidade sergipana e brasileira. Fazer um cotejo entre essas três mentalidades, eis tarefa deveras empolgante. Constante admirador

*. Conferência proferida a convite da Faculdade de Direito de Aracajú, reconstituída e completada pelo autor, à vista de notas taquigráficas. 
da obra de Tobias, de Sílvio Romero e de JoÃo Ribeiro, já fui tentado, certa vez, a escrever algo sôbre êste tema; estranho mesmo que os sergipanos ainda não o tenham realizado, pois assinalam êles três orientações intelectuais diferentes que não se repelem, ou se contradizem, mas, ao contrário, se exigem e se completam.

O arroubo criador de Tobias corresponde ao de Sílvio, porém em âmbitos distintos. Tobias Barreto era algo nietzscheano em sua pretensão de transmutar todos os valores nacionais, de operar uma reforma "ab imis fundamentis" nos costumes brasileiros, infundindo-lhes a seiva das idéias universais. Queria êle que a cultura tôda do ocidente se projetasse sôbre o Brasil, de um instante para outro, arrancando-nos do marasmo em que vivíamos. Sílvıo Romero participava de igual paixão reformista, mas olhava os problemas, digamos assim, do Brasil para fora, preocupado em vislumbrar nas linhas mestras de nossa cultura algo de original e próprio. JoÃo RIBEIRo veio acentuar ainda mais essa segunda tendência, de maneira mais tranqüila e objetiva, pela interpretação serena dos fatos históricos e sociais. Abria-se, dêsse modo, um terceiro momento na evolução histórica das idéias: o da compreensão sociológica e histórica da vida brasileira.

Quem passa, pois, de Tobias a Sílvio, e dêste a Joño RIBEIro, vai aos poucos tomando intimidade cada vez maior com as reservas naturais e expontâneas de nossa terra e de nossa gente.

Mas como Sergipe é pródigo em homens ilustres, surgiria depois um JAGKson DE Figueiredo para acentuar o toque necessário da tradição e das idéias universais.

De maneira que não é por acaso que estou fazendo esta visita ao vosso Estado. É quase que um dever dos homens de cultura do Brasil conhecer a gente sergipana, em homenagem a alguns dos mais penetrantes intérpretes de nossa consciência cívica e nacional. Tal emoção natural é aumentada, esta noite, pelas palavras tão amigas, sinseras e cordiais do ilustre diretor desta Casa, que fêz bem em estabelecer um contacto entre a Faculdade de 
Direito de São Paulo e a vossa. Efetivamente, muitos são os motivos de ligação e de compreensão entre as duas Casas de ensino.

Somos apenas o irmão mais velho na família dos juristas e no culto do Direito, olhando com simpatia e com entusiasmo o desdobrar-se de Faculdades de Direito pelas capitais do País, quando alicerçadas em sólido preparo científico. Ora, quando lemos uma revista como a que esta Faculdade de Direito publica, sentimos aumentar nossa confiança na capacidade realizadora dos juristas pátrios ${ }^{1}$. Tal convicção, que nasce dos escritos dos mestres, fortalece-se através do que também estão realizando os alunos. Bastaria a palavra do representante de vosso corpo discente, revelador de verdadeira vocação filosófica, para demonstrar que no Estado de Sergipe se mantém viva a tradição dos estudos, que se comunica de geração a geração como chama viva.

Foi por tais motivos, por conhecer o alto sentido espiritual da gente sergipana, que escolhi para esta noite o tema central do pensamento contemporâneo, a problemática dos valores.

De certa forma, as duas conferências que tenciono proferir em Sergipe estão ligadas por um nexo lógico substancial. Se na noite de hoje proponho-me apreciar o problema dos valores no pensamento atual, é minha intenção examinar amanhã alguns aspectos de minha concepção tridimensional do Direito, que é uma aplicação da axiologia no mundo jurídico.

2. As Filosofias, ou, por melhor dizer, as correntes filosóficas não surgem por acaso, nem constituem produto de elocubrações mentais solitárias, divorciadas da sociedade, livres do atrito dos valores humanos. Tôda autêntica corrente filosófica deve refletir as exigências essenciais de sua época, sendo certo que as doutrinas sòmente possuem universalidade e concretitude na medida em que logram traduzir algo de substancial nos horizontes de nosso ser histórico. 
A teoria dos valores é hoje central porque acima de tudo no mundo contemporâneo está em causa o valor do próprio ser humano. Jamais o homem se sentiu tão aflito, tão ameaçado; tão rico de saber e de ciência e, no entanto, tão carecedor de segurança e tranqüilidade. O mundo em que hoje vivemos, se nos surpreende, por certo decepcionaria aos pensadores do século passado, os quais, confiantes nos progressos das ciências e da técnica, se julgavam em condições de vaticinar uma época tranqüila, pela multiplicação dos bens materiais, pela disseminação do saber, pela possibilidade de comunicação mais pronta entre os povos, por todos aquêles elementos que sem dúvida alguma representam os benefícios da civilização chamada burguesa. Infelizmente, verificamos que assim não aconteceu. Haverá porventura quem não perceba, senão a angústia, pelo menos a inquietação e a perplexidade do homem no dealbar da era interplanetária? Desvendamos, é certo, prodigiosos mistérios da natureza, penetramos nos refolhos do átomo e descemos a camadas do ser que antes pareciam insondáveis; elevâmo-nos a altitudes jamais sonhadas, e, imitando o Criador, acrescentamos pretenciosos satélites ao nosso já pequeno planeta. Mas se dominamos cada vez mais a natureza, êsse domínio parece aumentar cada vez mais os motivos de preocupação sôbre o destino da espécie.

3. Era natural, por conseguinte, que sentíssemos necessidade de procurar no fundo de nossa consciência o foco irradiador da possivel paz espiritual. Volta, assim, a resplender o antigo ensinamento de SAnto Agostinho, aconselhando-nos a volver à intimidade da consciência, porque é nela que habita a verdade. Eis aí a razão pela qual surge uma problemática mais urgente do que a problemática do ser: é a problemática do valor, o que levou JÉAN WAHL a afirmar que "o homem é um militante do valor e não um cortesão do ser". Quando Maurice Blondel, o subtil filósofo da ação, nos lembra que a filosofia no século XX tem sido acima de tudo uma axiologia, uma teoria dos valores, está proclamando uma indiscutível verdade, pois até mesmo os neo-positivistas não podem deixar 
de tomar posição perante o grande tema, embora de maneira negativa ou reticente. Não quero dizer, porém, que a filosofia se reduza à filosofia dos valores, nem que tôda tarefa do filósofo se esgote na análise do que sejam os valores, no estudo das possibilidades de seu conhecimento, ou das formas pelas quais atuam sôbre a conduta humana. Penso, todavia, que o valor está no centro da filosofia, o que explica seja uma das preocupações básicas de sucessivos congressos de filosofia, ultrapassando, aliás, as lindes dos filósofos para invadir o campo da Psicologia e da Sociologia, abrindo-se perspectivas inéditas à compreensão de múltiplos problemas existenciais.

Perguntará alguém onde foram os filósofos buscar inspiração para a problemática dos valores. Aparentemente, a Axiologia ou a teoria dos valores foi apenas o desenvolvimento de um tema clássico da Economia Política. Na realidade, porém, a Filosofia sempre cuidou dos valores. A palavra não existia, mas os filósofos da Grécia Antiga ou da Idade Média, quando cuidavam dos problemas que estão merecendo alguns instantes de vossa atenção, referiam-se à problemática do ser sob certa perspectiva, ao ser enquanto bem, ou ao ser enquanto fim, objetivando explicar tanto a razão dos comportamentos humanos como o sentido dos fenômenos naturais. A teoria finalística ou teleológica do ser antecedeu à Axiologia, e, de certa forma, preparou o advento da compreensão autônoma dos valores, cujo estudo já agora constitui um pressuposto de qualquer consideração de ordem teleológica. É, por conseguinte, a meditação específica e prévia sôbre o mundo dos valores que representa uma das notas distintivas do pensamento de nossa época, que não se limita mais a investigar o sentido da existência humana ou, em geral, do ser do mundo, mas, como adverte F. JoAchim Von Rintelen, procura uma visão unitária a partir do fenômeno do valioso imediatamente dado, ou seja, da determinação ôntica do valor, em função das imagens do mundo (Weltbilder). 
4. O fato de terem sido os economistas os primeiros a dedicar atenção ao problema do valor, procurando determiná-lo em função dos conceitos de utilidade, de raridade, à luz da lei da oferta e da procura, ou em têrmos de puras relações matemáticas, é deveras eloqüente para comprovar-se a correlação essencial que existe entre êsse tema e o sentido da época em que vivemos.

Se a Economia Política chegou a ser concebida como ciência do valor, é que, sem dúvida, nenhuma época histórica teve, tanto como a nossa, a marca das preocupações produtivas e utilitárias.

Dessarte, quando KarL Marx, fundindo a dialética de Hegel e o materialismo de Fuerbach, desenvolveu a sua concepção da história fundada na fôrça modeladora dos meios de produção, não fazia mais do que estender para todos os ciclos históricos o acertado diagnóstico da época burguesa, efetivamente dominada pelo primado das valências econômicas.

Animado pelo mesmo espírito produtivista, que inspirara os mestres manchesterianos, desde AdAM SMITH a David Ricardus, o autor de $O$ Capital teve o mérito de correlacionar o fator econômico com os demais fatôres sociais, e, apesar de acentuar em demasia a importância da técnica de produção, até ao ponto de desnaturar a fisionomia complexa do processo histórico, soube revelar-nos que "capital", "trabalho", "valor", etc. são conceitos cuja determinação se liga à problemática filosófica e sociológica.

5. Na realidade, a noção de Marx nos dá de valor ultrapassa os horizontes particulares da ciência econômica, suscitando uma série de questôes de alcance universal.

Pois bem, ao mesmo tempo que o marxismo potenciava, histórica e sociològicamente, o conceito de valor, sofria êste o embate e o contraste das mais diversas e conflitantes teorias, cada uma delas refletindo um aspecto da matéria, segundo perspectivas unilaterais e incompletas. 
E tantas e tão antagônicas foram as perspectivas dos economistas que houve quem, traduzindo o geral desencanto, sustentasse ser preferivel o abandono definitivo do valor como tema positivo da ciência econômica, para se preferir apreciar, segundo critérios objetivos, de caráter matemático e estatístico, o sistema das relações de produção e de circulação das riquezas.

Como se vê, o valor transbordava do leito de Procusto dos economistas, projetando-se na plenitude dos horizontes históricos, como uma pergunta prévia sôbre a valia mesma do homem, cuja realidade ôntica passou a ser então considerada menos urgente do que a sua expressão axiológica. Antecipando, aliás, o sentido dos novos tempos já KANT, e depois dêle HEGEL, puzera em realce no conceito de pessoa, não o seu aspecto substancial, à maneira tradicional de BoÉcio, mas antes o seu significado deontológico.

De certa forma pode-se dizer que, à medida que o homem veio sentindo a carência de seu ser histórico, pôsto entre as aporias de uma civilização em crise, mais emergiu e se alargou a pergunta sôbre o destino da espécie, ou como costumo dizer, sôbre o dever ser do ser do homem.

Quando, por conseguinte, NiETzsche anunciou a inversão de todos os valores, proclamando que "o mundo se volta sempre para os inventores de valores novos", estava situando genialmente o problema nas coordenadas da temporalidade, demonstrando, em suma, que a axiologia deve se desenrolar cada vez mais em consonância com a teoria do homem e a teoria da história.

Dir-se-á que estou exagerando o alcance da crise de nosso tempo, comparável a tantas outras registradas no passado, e que, além do mais, bem ponderado o assunto, de crises se compõe tôda a tecitura da experiência humana.

Não há dúvida que a história é uma sucessão de mudanças e que, sob êsse prisma, há e haverá sempre crises. Não confundamos, todavia, as alterações operadas na superfície do fluxo histórico, ou as que assinalam simples eclosão ou amadurecimento de tendências que jả atuavam no bôjo das virtualidades existenciais, com as 
rupturas radicais que às vêzes se verificam no cenário histórico, cortando amarras que prendiam o batel humano a ancoradouros considerados definitivamente tranqüilos e certos.

São essas pròpriamente as crises de estrutura, distintas pela substituição de inteiras tábuas de valores, à cuja luz se configura e se afirma uma nova dimensão tanto do homem como do cosmos. Aliás, não há cosmovisão que não seja o concomitante situar-se do homem perante sî mesmo e as coisas.

Eis porque, repito, quando NiETzSche, reagindo contra o formalismo neo-kantiano e o otimismo empírico dos positivistas, anunciou que a humanidade se encontrava numa encruzilhada decisiva de transmutação de todos os valores, compreendeu que efetivamente não se tratava de uma simples passagem de um momento para outro da história, mas de algo mais profundo que dizia respeito à concepção mesma do homem.

Em verdade, tôda vez que ocorre uma crise de estrutura, altera-se a imagem do universo e do homem, dando lugar a uma nova compreensão da antropologia como ciência filosófica fundamental, à qual as ciências antropológicas particulares fornecem elementos sob o necessário ponto de vista empírico-positivo.

6. Ora, nos últimos decênios, a preocupação pelos assuntos axiológicos veio determinando uma série de pesquisas que já é possível ordenar de forma sistemática, não obstante o desconcertante multiplicar-se das teorias.

Já se pode falar em Ontologia dos Valores, destinada a pesquisá-los em sua estrutura e consistência; em Epistemologia dos Valores, empenhada na discussão dos métodos mais adequados à sua interpretação e vivência; em Sociologia ou Psicologia dos Valores, cujas contribuições visam determinar o sentido e o alcance das experiências valorativas do ponto de vista individual e coletivo; em Antropologia axiológica, na medida em que se procura, de um lado, resolver a delicada questão das tábuas de 
valores através da história, e, de outro, tipificar as possíveis "formas de vida" ou as categorias exemplares do homem, segundo a preponderância dêste ou daquele outro valor na variegada tipologia da existência humana.

Dirão uns que os valores são fatos psíquicos, ligados à vida afetiva, enquanto outros procurarão explicá-los como fenômenos volitivos etc.; haverá quem só encontre na Sociologia a resposta adequada ao problema ôntico do valor; mas não faltarão os convictos de sua "idealidade" ou "supratemporalidade", isto é, da objetividade ideal dos valores, concebidos como entes separados ou indiferentes às valorações contingentes e empíricas...

Análogo adejar de doutrinas será possível surpreender-se no plano epistemológico, uns pregando métodos intuitivos, sob as mais diversas modalidades, enquanto outros só admitirão acesso positivo ao mundo dos valores através das vias intelectivas ou de processos histórico-dialéticos, não faltando, para completar o quadro, agnósticos e céticos.

Não seria possivel, evidentemente, no breve transcurso desta conferência, alinhar as doutrinas fundamentais que se elaboraram e continuam a ser elaboradas sôbre tão grandes temas, e muito menos tentar uma síntese superadora das antinomias suscitadas pelos conflitos das perspectivas.

Se, como veremos logo mais, e já deflui do anteriormente exposto, o problema do valor, em última análise, implica essencialmente o da existência humana, nada de estranhável que não haja acôrdo, mas antes aporias $\mathrm{e}$ conflitos no trato da matéria. Nada mais contraditório do que o homem, dada a ambivalência essencial de seu ser pessoal, ora voltado para si mesmo, ora voltado para a sociedade; ora desejoso de estabilidade, ora seduzido pelo movimento; ora prêso às amarras do passado, ora projetado lìricamente para o futuro; ora impul̄sionado pelas fôrças dionisíacas da afetividade, ora sublimado pelas fôrças apolíneas da razão; sempre vacilante entre a certeza 
empírica de nexos causais imanentes e os planos encobertos da transcendência.

Polaridade do existir, polaridade do valor, num perene equilíbrio instável, através do qual se renovam os ângulos e as perspectivas da história, que constitui, sob êsse prisma, a experiência filosófica concreta.

Pelo mar agitado das interpretações axiológicas de nossa época não vamos, pois, tentar um vôo rápido de reconhecimento, que seria pouco fecundo e até mesmo inautêntico. Prefiro visualizar a questão a uma outra luz, procurando situar os grandes divisores axiológicos da cultura contemporânea, pondo em foco a raiz do divórcio ou do conflito ideológico entre o Ocidente e o Oriente, tomados êstes têrmos em mero sentido de prevalência geográfica. Interessar-nos-á, esta noite, mais o aspecto dramático, por assim dizer, da questão do que as subtis e penetrantes análises que ontólogos e epistemólogos nos têm brindado sôbre a consistência ou a cognoscibilidade dos valores ${ }^{1}$.

7. Comecemos pela análise da cosmovisão que seduz os povos comunistas, ao procurarem traduzir em realidade os ideais de KarL Marx. É claro que, à luz etiológica das idéias, desde o Mar do Norte e o Mediterrâneo até ao Pacífico, as chamadas repúblicas democrático-populares estão vivendo uma ideologia do Ocidente. O marxismo situa-se, histórica e ideològicamente, no processo evolutivo da cultura européia, de tal sorte que um chinês de MáoTse-Tung está hoje mais perto da Europa do que nos tempos do obscuro domínio ocidental.

Ora, o marxismo não é uma teoria econômica, como não é uma teoria política, ou uma doutrina filosófica, porque é tudo isto numa unidade indissolúvel. Seria falha tôda e qualquer apreciação crítica do marxismo que olvi-

1. Quanto a uma visão panorâmica dessas contribuições à Axiologia, permito-me lembrar as páginas que dediquei ao assunto no $1 .^{\circ}$ volume da minha Filosofia do Direito, 2. a edição, São Paulo, 1957. 
dasse o seu desenvolvimento sob o signo da categoria da totalidade, que dá sentido a cada problema particular na medida e enquanto o situa e o correlaciona concretamente no todo.

Em suma, o marxismo é, antes de mais nada, uma concepção do mundo, assente, como não poderia deixar de estar, numa concepção fundamental do homem, o que equivale a dizer, dos valores pelos quais o homem se empenha.

8. Para essa concepção o ponto nuclear e fundamental consiste na afirmação do primado do bem estar vital sôbre os valores que tradicionalmente são apontados como sendo os superiores na hierarquia espiritual. Para a teoria marxista o que há de substancial, de contínuo e de permanente, como fator determinante dos comportamentos individuais e coletivos, é o processo técnico de captação das fôrças da natureza para a elaboração dos bens indispensáveis ao bem estar humano. Não se trata, como alegam críticos superficiais, de uma concepção empírica e utilitarista, mas antes de uma ampla concepção que procura abranger os problemas da vida humana numa visão unitária, satisfazendo, assim, a um dos anseios naturais da inteligência perquiridora.

Há quem afirme, como por exemplo LeFÈBvre que o marxismo é um humanismo. Não lhe recuso tal qualificação, mesmo porque há muitas formas de conceber-se o humanismo. Sem dúvida alguma, seria absurdo recusar ao marxismo o desejo de perfectibilidade humana, a confiança numa humanidade melhor, redimida graças à sua própria potência revolucionária, segundo uma teoria embebida na praxis, mais destinada a transformar do que a interpretar o mundo.

Sob êsse ponto de vista, o marxismo não abandona aquela confiança nos poderes demiúrgicos da ciência e da técnica, nas quais, como vimos, os positivistas do século XIX haviam se revelado tão confiantes. A diferença é que os marxistas aliam à fôrça transformadora das ciências positivas a fôrça política propulsora e dominante da classe 
operária, do proletariado, visto por êles como o fruto por excelência das conquistas mais revolucionárias da sociedade burguesa e herdeiro necessário de um patrimônio que a burguesia decadente não estaria mais em condições de incrementar.

Não importa discutir aqui se, efetivamente, para Marx, Engels ou Lenine, é o fato econômico, como realidade por excelência, que plasma as superestruturas sociais, como seriam a Religião, o Direito, ou as Artes, ou se, ao seu ver, tais criações histórico-culturais adquirem valor próprio, condicionando, por sua vez, o projetar-se da infraestrutura produtiva. O que interessa é vê-los proclamar, sem discrepância, que tudo na história, ou é gerado por conflitos de interêsses econômicos ou se destina a superar tais conflitos, permanecendo, assim, quer genética, quer teleològicamente, o valor útil-vital no ápice da tábua axiológica.

No historicismo marxista, todo o fazer humano é governado pela fôrça imanente da progressiva socialização dos meios técnicos de produção, da qual deverá defluir, como conseqüência inevitável, a socialização das consciências, no sentido da participação de todos aos valores totais da comunidade, numa libertação total, conseguida graças ao desaparecimento das classes e à extirpação definitiva de tôdas as formas de alienação do homem. Daí a conclusão, nem sempre explicitamente confessada, mas implícita na doutrina, da liberdade como simples "consciência da necessidade", sendo o homem, mais do que livre, "condenado a ser livre”. É a liberdade compreensão como libertação na diàlética do processo histórico.

$\mathrm{Na}$ dramaturgia comunista, o resultado final da libertação, essencialmente coincidente com o têrmo final da alienação de um nomem a outro homem, só pođerá ser o fruto maduro da transformação social operada na infraestrutura econômica e em suas objetivações históricas, de sorte a assegurar "o govêrno das coisas", um ordenamento político-administrativo com tais características que nada resulte de atos decisórios eminentes, ocultando primados e 
supremacias de qualquer natureza: ào arbítrio de indivíduos ou de grupos dominantes substituir-se-á a expressão objetiva e espontânea de leis brotadas de iguais necessidades coletivas...

Nessa idéia basilar do "govêrno das coisas", ou seja, de uma vida social ordenada segundo fôrças imanentes, livres dos enganos e dos desvios que náscem dos atos decisórios, lateja uma desconfiança radical no individuo como tal, que se prefere conceber como simples momento de um processo total englobante, como aparelho de rádio sintonizado segundo um mesmo e indeclinável comprimento de onda, a fim de que só valha, em última análise, o todo.

Exacerba-se, na doutrina marxista, a subordinação do indivíduo ao todo, já postulada pela filosofia hegeliana. Note-se, no entanto, que para HEgel, o Estado, - apesar de constituir a plenitude da realização ética, - não é senão o momento culminante do Espírito Objetivo: acima dêle, superando-o, desenvolvem-se os momentos do Espirito Absoluto, como Arte, Religião e Filosofia.

Para KARL MARx, ao contrário, a sociedade se converte no Absoluto, nada sendo possivel conceber-se fora ou acima dela. Dai a compreensão da Arte, da Religião e da Filosofia como instrumentos da praxis revolucionária, a serviço da coletividade.

É certo que para preparar o advento da libertação total, o marxista prega e legitima, por tempo imprevisível, a ditadura do proletariado; não é menos certo que para o triunfo fatal do espontâneo e do objetivo postula-se a praxis consciente, o desencadeamento do processo revolucionário, mas não se deve esquecer a nota anárquica que se oculta no âmago do marxismo originário, postos os olhos numa comunidade ideal sem Estado, enquanto centro de referência de poder e de domínio, por se terem tornado socializadas e complementares as liberdades, com base na socialização harmônica dos meios de produzir.

Quando o marxista anuncia, pois, o futuro "govêrno das coisas", na fase final do "Estado evanescente", não 
está empregando a palavra "coisa" no sentido material daquilo que oferece ao homem certa resistência, mas se refere a tudo que se atualize como estrutura, organização, ou objetivação neutra espontânea. Não o primado da liberdade, mas do sistema; não a excelência das dedicações pessoais, mas das estruturas burocráticas; não a confiança nas reservas éticas da livre iniciativa, mas apenas e tão sòmente o frio comando dos cálculos estatísticos, prevalecendo, assim, a planificação, o dirigismo, a coisificação dos serviços públicos e das formulações jurídicas. Êste é o sentido real e exato da pretensão de subordinar o homem às coisas, o que pressupõe, por conseguinte, o predomínio absoluto do valor do todo sôbre o valor de seus elementos componentes.

Essa relação entre todo e parte é que nos fornece a chave da diferenciação a ser feita entre os dois mundos que hoje disputam os quadrantes da história.

9. Postos assim os dados da questão, dever-se-á concluir que, em contraposição ao totalitarismo comunista, o Ocidente esteja defendendo a tese do pluralismo das iniciativas, fundado no valor irrenunciável de cada homem no seio da ordem jurídico-política?

Assim deveria ser, ou melhor, deve ser, mas não é dito que o mundo ocidental esteja pautando sempre os seus atos em consonância com os ditames dêsse dado axiológico fundamental.

Na realidade, muitas vêzes fico a pensar se há diferença entre ser "governado pelas coisas" na totalização unitária do Estado soviético, ou através de certas estruturas empresárias e governamentais dos regimes democráticos, que modelam a sociedade ocidental à sua imagem e semelhança, fabricando o homem-massa mais conveniente às exigências do mercado consumidor ou dos prélios eleitorais.

Tanto vale tratar os homens como se fôssem "coisas" no momento deontológico da praxis, sob prisma indivi- 
dualista ou coletivista, pois que o resultado desolador será sempre idêntico.

De certo ponto de vista, embora tal afirmação possa causar escândalo, ainda a teoria marxista teria a seu favor, para legitimá-la, a esperança remota de uma libertação obtida graças ao desaparecimento da luta de classes, enquanto que no Ocidente "coisifica-se" o homem sem se visar algo de superior ao processo de sua crescente instrumentalização, invocando-se, talvez, a título explicativo, os indices estatísticos inegáveis da participação cada vez maior do povo na fruição dos bens produzidos.

Mister é, porém, que a causa do Ocidente seja mais conscientemente correlacionada com os alvos que a dignificam, revelando-se insuscetivel de confundir-se com o ideal marxista, pelo valor radical da liberdade que a informa.

Em um trabalho intitulado Liberdade $e$ valor, que redigi como um dos relatores do XII Congresso Internacional de Filosofia, realizado em Veneza, em 1958, penso ter mostrado a correlação essencial entre aquêles dois conceitos, e que as diferentes concepções axiológicas poderiam ser distintas segundo a maneira de situar-se a liberdade no sentido total da existência humana.

10. No entanto, há quem considere dispensável e até mesmo nociva qualquer cogitação sôbre os problemas axiológicos, reputados "destituídos de sentido".

Tomados pelo desejo de não aceitar senão o verificado, - quer analiticamente, através de reduções lógicoformais, quer sintèticamente, através da experiência, - os neo-positivistas reputam os temas axiológicos de caráter irracional, suscetiveis de ser analisados apenas como fatôres determinantes da ação, segundo critérios puramente estatísticos.

Quando se arreda da Filosofia a problemática do homem e aos poucos se reduz o filósofo a um especialista a serviço da certeza científica, perde-se a visão compreensiva do todo; e, julgando-se livre de pseudo-problemas, 
na realidade o pensador acaba escravizado a uma compreensão unilateral e falha do real, sem nos poder dizer, além do mais, como lhe foi possível verificar que só o verificável analítica ou experimentalmente corresponde à verdade...

O positivismo clássico, de Augusto Comte e Herbert SPENCER, apesar de algumas interpretações discutíveis do homem e do cosmos, tinha o mérito de constituir uma "totalidade de compreensão", na qual era dado aos homens situar-se, consoante subtil ponderação de Francisco RomeRo, "tanto para viver como para morrer".

Ao contrário, o neo-positivismo, se, de um lado realiza uma tarefa benéfica, exigindo mais rigor conceitual e mais precisas formas expressionais, contribuindo para o apuro da linguagem lógico-científica, — de outro lado, descamba para a eliminação progressiva daqueles problemas que, por dizerem respeito ao destino humano, estão hoje mais diretamente em causa.

Nenhuma doutrina é tão frágil, como a do neo-empirísmo, para contrapor-se à ideologia comunista que tem a fôrça de uma cosmovisão, capaz de abranger o político e o militar, o cientista e o proletário numa "totalidade de sentido".

A nota de renúncia ou de abstenção de problemas, característica de certas tendências neo-positivistas, foi admiràvelmente assinalada por Ferrater Mora ao lembrar que para WitTGENstein, por exemplo, "as questões não devem ser resolvidas, mas dissolvidas", apresentando-se, assim, como um anti-Sócrates, visto não pretender êle suscitar dúvidas para dar nascimento ao conceito, segundo o processo maiêutico, mas visar antes uma terapêutica tendente a por fim ao malestar e às inquietações oriundas do conceito, o que corresponderia ao método tafêtico ou funerário.

Não é de uma Filosofia supressiva de problemas, nem de outra, também em voga, opressiva, desesperançada e não menos hostíl às sínteses superadoras da Razão que carece o Ocidente, porém, de uma renovada concepção do 
homem e do cosmos, na qual se correlacionem e se polarizem em unidade orgânica as exigências das partes e do todo, e se dialetizem, em unidade concreta, ser e dever ser, assim como os valores do intelecto e os da objetividade, primando, porém, em surgindo a necessidade de optar, a liberdade sôbre a organização.

Sòmente essa compreensão dialética, sempre aberta ao influxo de novas circunstâncias e valores, é que poderá servir de base à mútua compreensão daqueles que aspiram à totalidade, mas não amam menos a multiplicidade das perspectivas. Ao monismo ideológico dos marxistas, reduzidos a dedilhar as variantes talmúdicas das obras de MarX ou Lenine, necessário é contrapor, como decorrência da reconhecida liberdade constitutiva do Espírito, o pluralismo das filosofias coexistentes, no diálogo fecundo possibilitado pela convicção do valor radical da pessoa humana e de que "o limite da liberdade só pode ser outra liberdade".

11. Não haveria, com efeito, outra saída senão acolher as conclusões marxistas se efetivamente a consciência do homem fôsse mera resultante das relações econômicas de produção, desaparecendo, assim, qualquer distinção entre realidade e consciência, tal como o proclama o materialismo dialético.

Estou convencido, porém, de que a verdade está com aquêles que, como Gabriel Marcel, reputam o homem livre na medida em que se negar como coisa.

Longe de "coisificar-se", subordinando-se às linhas inflexíveis imanentes ao já acontecido, deve-se reconhecer que o homem vai projetando a sua tonalidade especifica sôbre tudo que o cerca: os valores, no fundo, refletem a dimensão humana acrescida às coisas das quais o homem se serve em sua renovada faina histórica. $O$ que disse Espinosa da beleza (a beleza é um acréscimo do ser) poder-se-á dizer de todos os valores.

Desde a arma de silex mais rudimentar, talhada pelo homem primitivo, na ânsia de defesa ou de domínio, até 
às mais surpreendentes criações da Física hodierna, tudo são "humanizações" das coisas, insuscetíveis de serem compreendidas com abstração do Espírito, revelador de formas inéditas na natureza.

Não resta dúvida que a "cultura", ou seja, no dizer conhecido de Simmel, o patrimônio de espiritualidade tornado objetivo pela espécie humana através dos tempos, é essencial à determinação da "imagem do homem". Esta ficaria mutilada se fizéssemos abstração do mundo histórico, do complexo de bens materiais e espirituais em que o espírito humano se refletiu e que, uma vez constituídos, passaram a condicionar os atos criadores das gerações supervenientes.

Não houvesse a objetivação das intencionalidades no sistema dos bens culturais, e teria sido precário o diálogo das gerações, o intercâmbio espiritual dos ciclos históricos. Penso assistir razấo a Golingood quando adverte que, no fundo, não há civilizações estanques, ou totalmente extintas, pois elas se comunicam através de múltiplos processos de compreensão, atuando sôbre as posteriores em várias formas de recepção de idéias e valores.

O homem é, pois, também a sua "herança histórica", aquilo que já se tornou fato e que, como tal, atua sôbre os comportamentos atuais e futuros.

Às vêzes somos levados a exagerar a importância desta ou daquela objetivação cultural, sejam elas os processos técnicos de produção econômica ou as estruturas jurídico-políticas, e, então, perdemos contato com o foco de que promanam os cabedais de conhecimentos, de utilidades ou de formas estéticas, que distinguem as diversas civilizações e idades.

É preciso, por conseguinte, - e essa é uma necessidade que se torna imperiosa quando se deflagra uma crise de estrutura, - transcender o mundo do "criado" ou do "constituído" para atingir-se o centro irradiante, o fulcro revelador incessante das "formas" que envolvem a natureza e a dominam e a põem a serviço de fins humanos. 
Quando nos elevamos à fonte primeira da cultura, o que se nos revela é o homem em sua auto-consciência espiritual, ou, por outras palavras, o Espírito como liberdade constitutiva, que dá significado às "coisas", ao construído e ao sistematizado, ao "fático" e ao "normativo", que tudo se subordina ao valor primordial, como os rios mais caudalosos remontam à fôrça original e plúrima de seus mananciais.

12. Não nos deixemos, pois, iludir pelo esplendor das "obras", com esquecimento do "pensamento" que nelas pulsa. Vêde aquela máquina, harmoniosa no rítmo sincrônico de polias e engrenagens, obedecendo com precisão micrométrica a comandos remotos; é aço, é alumínio, são fios, válvulas, bobinas, tudo o que há de mais material e físico, e, no entanto, não nos iludamos: aquela máquina é o resumo feliz de milênios de história, albergando os instantes criadores que iluminaram de súbito as vias ascencionais das hipóteses triunfantes, assim como as longas e penosas jornadas gastas por sábios absortos em seus laboratórios, por operários no bulício das usinas, por empreendedores lançados no campo do lucro e do risco.

O rítmo da máquina reproduz, no fundo, o pulsar do coração humano. Através dela, como se fôra uma lente aproximadora de imagens temporais, vejo séquitos de trabalhadores do braço, do capital e da inteligência; vejo projetando-se, em esfôrço diuturno e confiante, o Homem, sim o Homem, na sua afirmação pessoal, como raiz de todos os valores.

13. Certa vez, discutia-se no Parlamento britânico se, para erguer uma barragem no Nilo, valia a pena sacrificar um templo do mais alto significado histórico; ficaram os presentes ondulando entre motivos estético-culturais e utilitários. E houve quem sentisse, em tôda a sua profundidade, o problema axiológico subjacente, ao formular uma pergunta estarrecedora: "Se numa casa em chamas houvesse uma criança num berça e uma obra prima de Rafael, 
e se fôsse mister optar com urgência entre uma ou outra, qual delas deveria ser salva?"

Embora sem sentirem a crueza do exemplo lembrado, há homens que tudo sacrificam para a salvação das coisas, nem se apercebem dos gemidos e dos gritos de dor e de revolta que vão semeando em sua marcha inexorável. Outros há, ao contrário, que põem a tônica do amor nos valores da pessoa do próximo, sabendo amar, na concretitude imediata do possível, a humaniddade genérica e abstrata. Tais homens não vacilariam um instante sequer em salvar a criança, e através dela, o valor por excelência, que é o próprio homem visto como valor-fonte de todos os valores.

Tudo no homem são polaridades. Vive e, quanto mais vive, mais se destina à morte. Cria, e, no momento culminante da criação, desprende-se-lhe a imagem, a forma, a idéia. Refugia-se em si mesmo e no seu refúgio carrega consigo os outros, a sociedade e o Estado. Realiza a justiça, cultiva a beleza e a verdade, e, quanto mais multiplica os atos de amor e de justiça, de ciência e de beleza, mais sente carência dêsses valores, mais se mostra sedento de justiça, de amor, de beleza, de verdade.

Como, então, querer esvaziar o homem de seus ideais, do dever ser que é a razão de ser de sua existência?

Eis aqui a verdade fundamental, que nos entreabre os pórticos do reino dos valores: o ser do homem é o seu dever ser, porque só êle, dentre todos os entes, de maneira originária (e não derivada, como ocorre com os bens de cultura, desde os econômicos aos artísticos) é enquanto deve ser.

Se atentarmos, todavia, nessa dimensão radical do homem, na polaridade que se põe entre ser e dever ser, entre realidade e ideal, nos horizontes da Axiologia uma luz resplandece e, embora não possa o homem apreendê-lo, um valor se intui, de que os demais todos são reflexos, o Valor que é pressuposto e razão da vida, em virtude do qual lateja na raiz de nós mesmos congênita carência de ideal e de perfectibilidade. 